\title{
ProQuest
}

\section{The medium-to-long-term outcome of Papua New Guinean children after cardiac surgery.}

Tefuarani N, Vince J, Hawker R, Sleigh A, Williams G. Annals of Tropical Paediatrics. Abingdon: Mar 2004.

Vol. 24, Iss. 1; pg. 65

\section{Abstract (Summary)}

This study reports the medium-to-long-term outcome in Papua New Guinean (PNG) children selected to undergo cardiac surgery at the Royal Alexandra Hospital for Children in Sydney, Australia between 1978 and 1994. Follow-up ranged from 4 to 20 (median 11) years. The cohort comprised 125 children who had surgery and 31 who were initially selected in PNG for surgery but who on further investigation were found to be unsuitable. Through strenuous attempts, local health workers, the media and village and church leaders traced $122(98 \%)$ of the operated and $29(94 \%)$ of the non-operated children. One of the operated children and six of the non-operated children had died, giving respective survival rates among those traced of $99 \%$ and $79 \%$. Altogether, 106 (88\%) of the 121 operated and 20 (87\%) of the 23 non-operated survivors were reviewed. Ninety-nine (93\%) of the surgical patients were asymptomatic and all fulfilled the New York Heart Association criteria (NYHAC) class I or II. Mild pulmonary hypertension or residual defects of no haemodynamic significance were present in 47 (44\%). In contrast, all 11 survivors from the 18 children originally classified as having inoperable lesions were symptomatic, all in NYHAC classes III or IV, six were on cardiac medication and four had been admitted at least once in the previous year. Ninety-two of $96(96 \%)$ of the surgical group had a normal exercise test and 75 of $96(78 \%)$ had normal chest X-rays. Thirty-nine of 99 had a normal electrocardiogram whilst the remainder had changes related to the underlying lesion and the surgery performed. This study shows that the PNG children who had cardiac surgery at RAHC between 1978 and 1994 had good medium-to-long-term survival.

\section{Indexing (document details)}

MeSH subjects:

Adolescent, Adult, Child, Child, Preschool, Female, Follow-Up Studies, Heart Defects, Congenital -- mortality, Heart Defects, Congenital -- surgery, Humans, Male, Papua New Guinea -- epidemiology, Postoperative Complications -- mortality, Quality of Life, Survival Rate, Time Factors, Treatment Outcome

Author(s): Tefuarani N, Vince J, Hawker R, Sleigh A, Williams G

Document types: Journal Article

Publication title: Annals of Tropical Paediatrics. Abingdon: Mar 2004. Vol. 24, Iss. 1; pg. 65

Source type: Periodical

ISSN: 02724936

ProQuest document ID: 803792351

Document URL:

http://proquest.umi.com/pqdweb?did=803792351\&sid=1\&Fmt=2\&cli entld=20870\&RQT=309\& VName $=$ PQD 